\title{
Post-translational control of protein function with light using a LOV-intein fusion protein.
}

\author{
D. C. Jones, ${ }^{a}$ I. N. Mistry and A. Tavassoli ${ }^{a}$ \\ Methods for the post-translational control of protein function with light hold much value as tools in cell biology. To this \\ end, we report a fusion protein that consists of DnaE split-inteins, flanking the light sensitive LOV2 domain of Avena Sativa. \\ The resulting chimeria combines the activities of these two unrelated proteins to enable controlled formation of a \\ functional protein via upregulation of intein splicing with blue light in bacterial and human cells.
}

\section{Introduction}

Inteins are naturally occurring protein domains that self-excise from a host protein by an autocatalytic process. Inteinmediated protein splicing results in the adjacent $\mathrm{N}$ - and $\mathrm{C}$ terminal peptide chains (known as exteins) being joined by a peptide bond, to give a functional, mature protein. The ability of inteins to join two protein fragments with high specificity and selectivity has resulted in their extensive use for a variety of biotechnological applications. There is also significant potential for methods that enable intein splicing to be selectively triggered by an external stimulus; this would allow the activity of a given protein to be regulated post-translation, enabling initiation of a given protein's function with high special and temporal control in living cells (via activation of intein splicing and excision of the intein domain). The majority of current approaches involve fusing an additional domain to an intein so that splicing is allosterically triggered by either a small molecule, ${ }^{1-4}$ changes in $\mathrm{pH}^{5}$ or temperature ${ }^{6,7}$ Although these approaches allow protein splicing to be triggered throughout a given sample, they do not allow special or temporal control of activity within a subset of the sample. This limitation has been overcome by replacing key residues required for splicing with photocaged non-natural amino acids, which enables intein-splicing to be initiated with UV light. ${ }^{8-12}$ While potentially very powerful, these approaches necessitate amber codon reassignment and so require the incorporation of an orthogonal tRNA/tRNA synthetase pair into the targeted living system.

We envisaged an alternative approach to engineering photoregulation into inteins, whereby the coupling of a light sensitive protein domain to an intein results in functional combination of the activities of these unrelated proteins. The Avena Sativa Light Oxygen Voltage 2 (LOV2) domain, which undergoes a marked change in protein structure upon exposure to blue light, has been previously used to directly engineer photocontrol into several proteins. ${ }^{13}$ The photochemistry of the LOV2 domain is determined by the properties of a flavin mononucleotide ligand whose excitation by a photon leads to the formations of a cysteinyl adduct, resulting in a number of conformational changes that lead to the dissociation of an $\alpha$-helix (called the J $\alpha$-helix) from the main body of the protein. ${ }^{14}$ We hypothesized that the change in conformation and spatial orientation of the J $\alpha$-helix upon exposure of LOV2 to blue light may be exploited to regulate the splicing a split intein (Figure 1A). We chose a mutant form of the Nostoc punctiforme (Npu) DnaE trans intein for this purpose for two reasons; ${ }^{15}$ first, its high tolerance to amino acid variations at the splicing junction would allow the function of a variety of exteins to be controlled with the resulting chimeric protein. ${ }^{16}$ Second, we reasoned that as the splice time of $\mathrm{Npu}$ inteins ${ }^{17,18}$ is less than the recovery half life of the LOV2 photo-adduct, ${ }^{19}$ intein splicing would occur prior to recovery of LOV2 back to its dark state.

Whilst this manuscript was in preparation, Truong and coworkers reported photoactivated trans splicing by fusing LOV2 to a truncated C-terminal Npu intein. ${ }^{20}$ Here, we detail the a generally applicable method that utilizes LOV2 for the photocontrol of cis splicing of $\mathrm{Npu}$ inteins.

\section{Results}

\section{Light-activated intein splicing in E. coli}

We initially constructed a cassette encoding a fusion protein consisting of the $\mathrm{N}$-terminal $\mathrm{Npu}$ intein, follower by LOV2, followed by the C-terminal $\mathrm{Npu}$ intein (referred to as InN-LOV-

\footnotetext{
a. Chemistry, University of Southampton, Southampton, SO17 1BJ, UK. E-mail: a.tavassoli@soton.ac.uk

Electronic Supplementary Information (ESI) available: Supplementary Figures 1-7 See DOI: $10.1039 / \times 0 \times x 00000 x$
} 
A

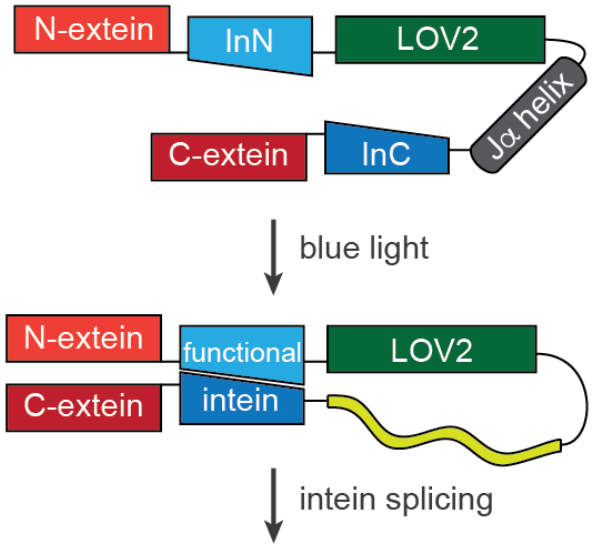

spliced protein
B

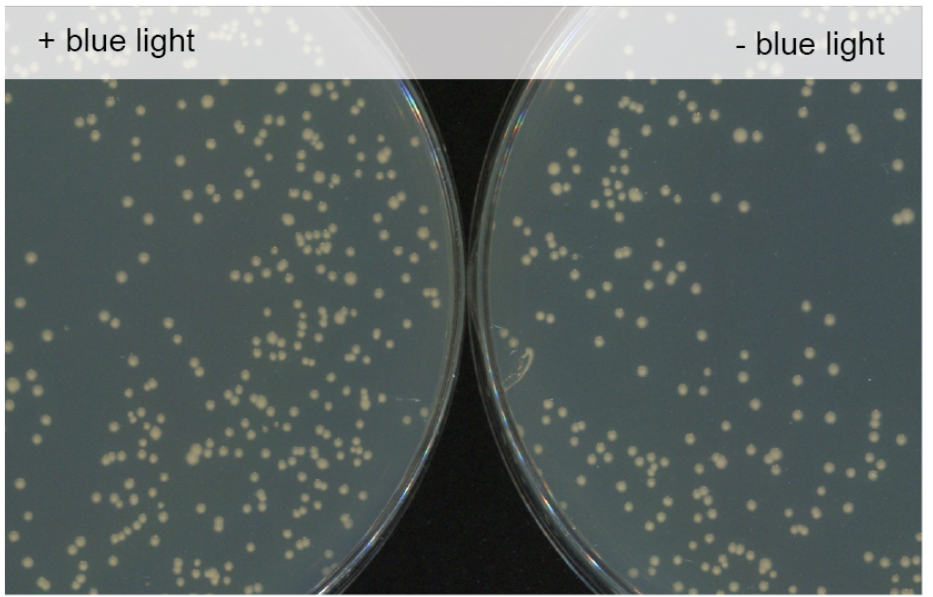

C

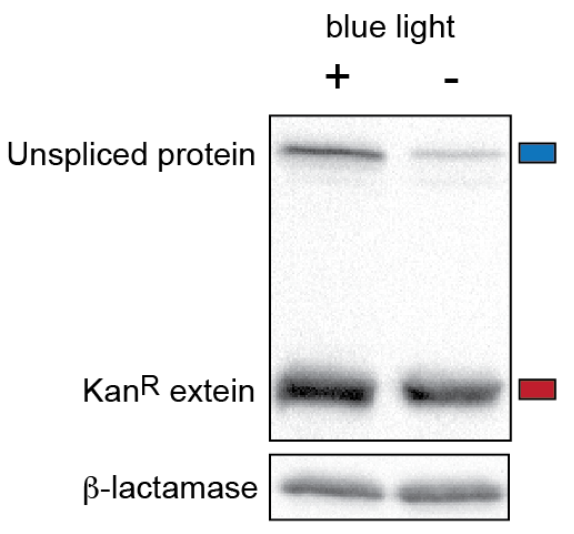

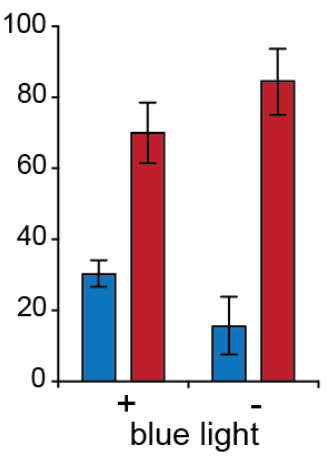

D

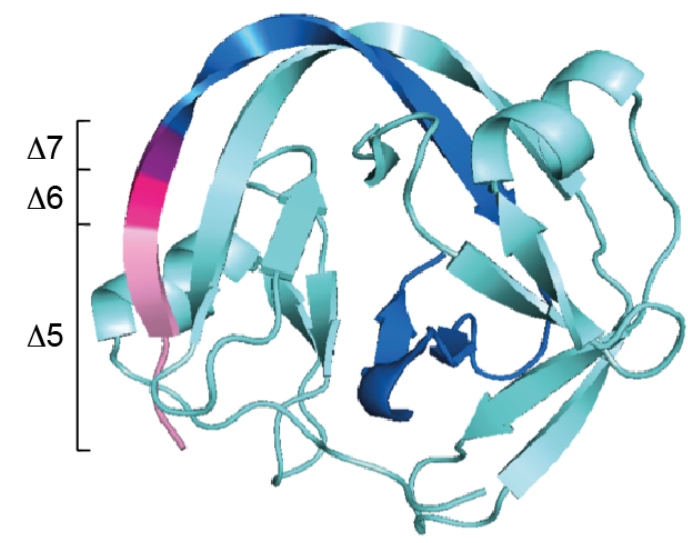

Figure 1. Light activated protein splicing with a LOV-intein chimeric protein. A) A fusion protein consisiting of the LOV2 domain, flanked by N-and C-terminal inteins (InN and InC) and N-and C-terminal extein halves would be expected to undergo conformational change upon exposure to blue light, initiating protein splicing to give

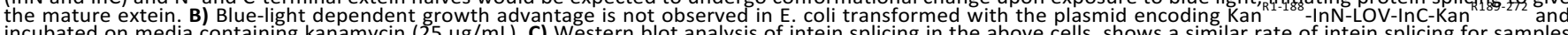
incubated on media containing kanamycin $(25 \mu \mathrm{g} / \mathrm{mL})$. C) Western blot analysis of intein splicing in the above cells, shows a similar rate of intein splicing for samples grown in the dark, or under blue light. D) Structure of the Npu inteins, showing the amino acids deleted in the InN-LOV- $\Delta 5 \operatorname{lnC}$, InN-LOV- $\Delta 6 \operatorname{lnC}$, and InN-LOV- $\Delta 7 \operatorname{InC}$

InC from here). Neomycin phosphotransferase, which imparts kanamycin resistance (referred to as kan $^{\mathrm{R}}$ from here), was split between F188 and S189 and the two resulting fragments used as exteins that flanked either side of $\ln N$-LOV-InC to give a plasmid encoding Kan ${ }^{\text {R1-188 }}$-InN-LOV-InC-Kan ${ }^{\text {R189-272 }}$ (referred to as $\mathrm{Kan}^{\mathrm{R}}$-LOV-intein). It should be noted when choosing the site to split a potential extein, that the mechanism of intein splicing requires a cysteine or serine as the first amino acid of the second extein fragment (joined to the C-intein). E. coli were transformed with the above plasmid and incubated overnight on media supplemented with kanamycin at $37^{\circ} \mathrm{C}$, either in the dark or under blue light from a LED array (Supplementary Figure 1).

If splicing of $\mathrm{Kan}^{\mathrm{R}}$-LOV-intein is regulated by blue light, more colonies would be expected to be present on plates incubated under blue light than those grown in the dark. There was however no change in the number or size of surviving colonies between the samples (Figure 1B), indicating that the InN-LOVInC fusion protein splices even in the absence of blue light. We further assessed this by western blot (Figure 1C), and observed a high rate of splicing, with no difference between samples incubated under blue light and those grown in the dark. Given this observation, we reasoned that the high affinity of the $\mathrm{N}$ and C-terminal $\mathrm{Npu}$ intein fragments for each other is either overriding, or affecting LOV2 photoswitching. To probe this, we measured the recovery of photoactivated LOV2 via the half-life of the flavin mononucleotide-cysteinyl adduct. ${ }^{21}$ We observed a significant reduction in the half-life of photoadduct decay in the InN-LOV-InC chimera, from $58 \pm 0.3$ seconds for LOV2 (Supplementary Figure 2) to $24 \pm 0.1$ seconds for $\ln N$ LOV-InC (Supplementary Figure 3). This suggested that the Npu inteins destabilize the photoactivated form of LOV2. We reasoned that this was due to the high affinity of $\mathrm{Npu}$ intein fragments for each other, and that reducing this affinity should also reduce the effect of the inteins on LOV2 photoswitiching, potentially enabling light-activated protein splicing. Previous work has shown that deleting the first 6 amino acids from the $\mathrm{N}$-terminus of the Synechocystis sp. PCC6803 DnaE C-intein is sufficient to eliminate the binding and splicing of $\mathrm{N}$ - and $\mathrm{C}$ inteins. ${ }^{22}$ We therefore constructed plasmids encoding $\ln N$ LOV-InC with deletions of 5, 6 or 7 amino acids from the $\mathrm{N}$ terminus of the Npu C-intein (Figure 1D). As before, Split Kan ${ }^{R}$ 


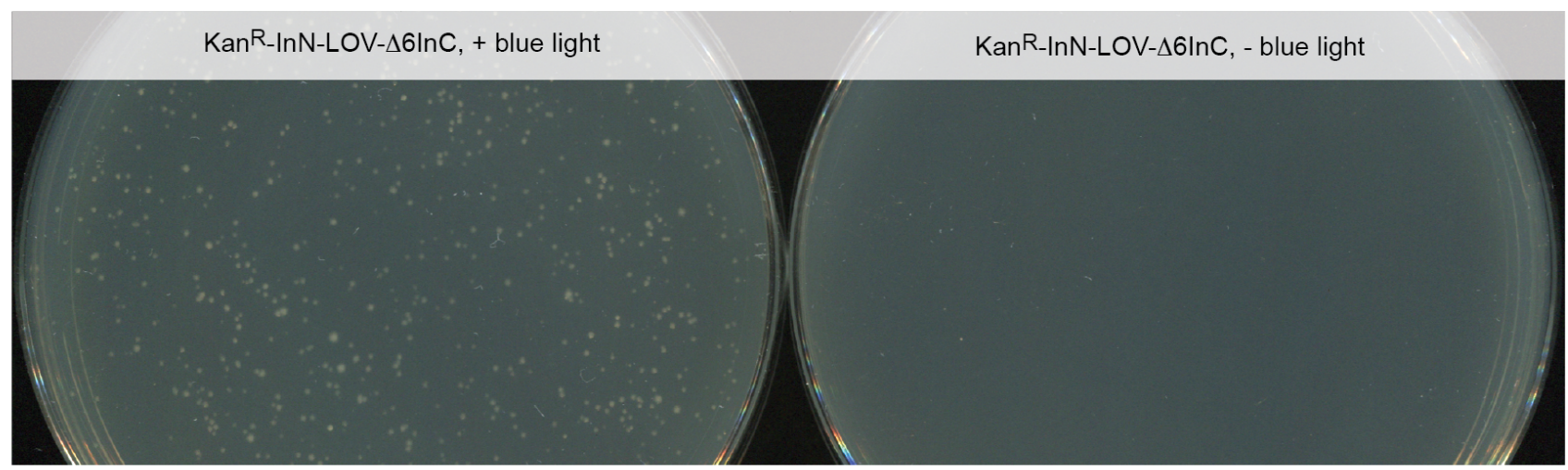

B

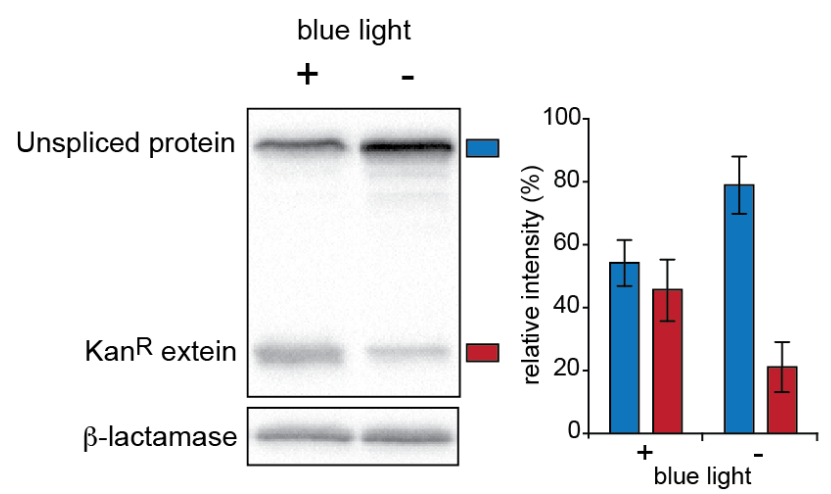

C

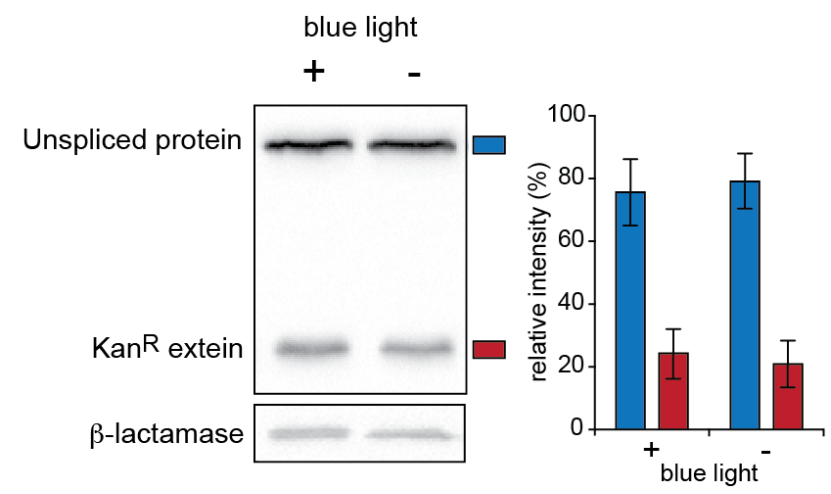

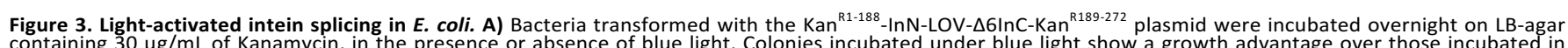
containing $30 \mathrm{\mu g} / \mathrm{mL}$ of Kanamycin, in the presence or absence of blue light. Colonies incubated under blue light show a growth advantage over those incubated in the dark. B) Western blot analysis of intein splicing shows a $\sim 2$-fold increase in spliced extein (Kan ${ }^{\mathrm{R}}$ ) in bacterial incubated under blue light, compared to those
incubated in the dark. C) The effect from blue light is eliminated when using dark-locked LOV ${ }^{4505}$ protein, showing that the above effect is dependent on a functional incubated in the dark. C) The effect from blue light is eliminated when
LOV2, and not a result of blue light directly affecting intein splicing.

was used as the exitein. E. coli were transformed with these plasmids and incubated overnight on LB agar containing kanamycin, either in the dark, or under blue light. Bacteria transformed with the plasmid encoding Kan ${ }^{\text {R1-188 }}$-InN-LOV$\triangle 5$ InC-Kan ${ }^{\text {R189-272 }}$ did not show growth advantage under blue light (Supplementary Figure 4), while those transformed with the plasmid encoding $\mathrm{Kan}^{\mathrm{R} 1-188}$-InN-LOV- $\Delta 6$ InC-Kan ${ }^{\mathrm{R} 189-272}$ grew significantly better under blue light than in the dark (Figure 2A). Bacteria transformed with the plasmid encoding Kan ${ }^{\text {R1-188 }}$ InN-LOV- $\Delta$ IInC-Kan ${ }^{\text {R189-272 }}$ did not grow in the dark, or under blue light (Supplementary Figure 5 ). These results suggest that deletion of 5 amino acids from the $\mathrm{N}$-terminus of the $\mathrm{C}$ terminal intein does not sufficiently reduce the affinity of the $\mathrm{Npu}$ intein fragments to allow control of splicing by LOV, whereas deletion of 7 amino acids reduces the affinity of the intein fragments to the extent that they are no longer able to splice. Deletion of 6 amino acids from the C-intein however, reduces the affinity of the intein fragments to the extent that the conformation change of LOV upon photo-activation regulates splicing. We further examined the effect of blue light on InN-LOV- $\Delta 6$ InC splicing in these cells by western blot. Cells transformed with this plasmid were grown without selective pressure for the spliced extein (i.e. in the absence of kanamycin), and protein levels between samples was normalized using $\beta$-lactamase levels, which is expressed from the same plasmid as the InN-LOV- $\Delta 6 \operatorname{lnC}$. We observed around $\sim 2.5$-fold higher levels of spliced $\operatorname{kan}^{\mathrm{R}}$ protein in bacteria incubated under blue light than those grown in the dark
(Figure 2B). Comparing the ratio of the unspliced intein to the spliced extein between InN-LOV-InC (Figure 1C) and InN-LOV$\triangle 6 \mathrm{InC}$ (Figure 2B) suggests that the splicing of the InN-LOV$\triangle 6 \mathrm{InC}$ is less efficient in comparison, probably due to the reduced affinity of the Npu intein fragments, but is nonetheless regulated by LOV2 photoactivation. Analysis of the kinetics of LOV switching in InN-LOV- $\triangle 6 \ln C$ sheds further light on the mode of action; the half life of the LOV2 flavin mononucleotide-cysteinyl adduct in the InN-LOV- 6 InC protein was measured as $38 \pm 0.7$ seconds (Supplementary Figure 6), which is around 2-fold slower than the original InN-LOV-InC protein. This supports our hypothesis that the affinity of the $\mathrm{Npu}$ intein fragments was affecting the photoswitching of LOV2. The kinetics of photoswitching of similar inteins has recently been reported to be 2-3 hours (an instant response is observed, which plateaus to a maximum after $\sim 150$ minutes). ${ }^{20}$ The level of LOV-independent splicing, and the effect of blue light on the splicing of $\mathrm{Npu}$ inteins was measured using a C450S mutant of LOV2 that has previously been shown to be locked in its dark state even in the presence of blue light. ${ }^{23}$ We observed no difference in spliced extein levels in samples incubated in the dark or in the presence of blue light (Figure $2 \mathrm{C}$ ), indicating that a functional LOV2 domain is required for the regulation $\operatorname{lnN}-L O V-\triangle 6 \operatorname{lnC}$ splicing with blue light. Interestingly, incorporation of $\mathrm{LOV}^{\mathrm{C} 450 \mathrm{~S}}$ into the original $\mathrm{Kan}^{\mathrm{R}}$ InN-LOV-InC complex had no affect on the relative levels of 
A
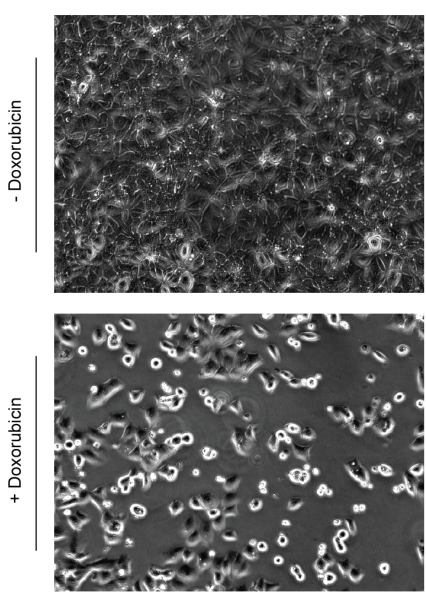

B

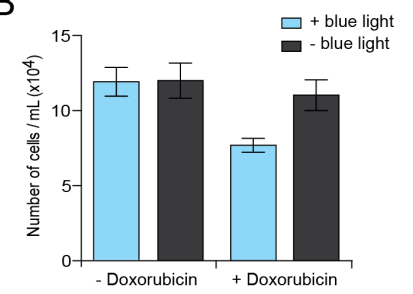

p17-LOV- $\Delta 6$ intein - blue light
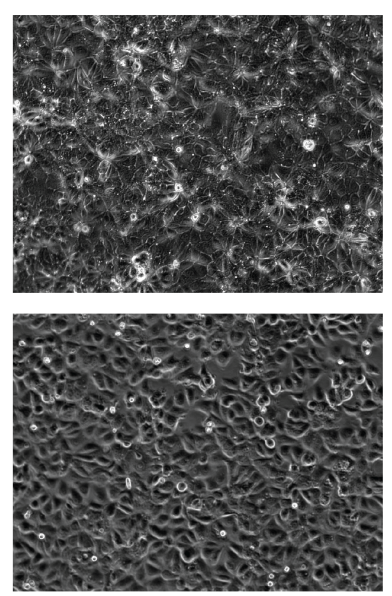

C

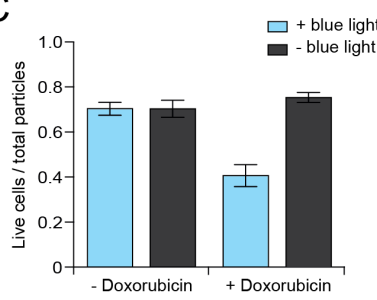

Figure 4. Light-activated intein splicing in human MCF7 cells. A) Micrographs of MCF7 cells transfected with the p17-InN-LOV- $\Delta 6$ InC-p12 plasmid, cultured with or without $10 \mu \mathrm{M}$ doxorubicin, in the dark or under blue light. A reduction in cells cultured in blue light and with doxorubisin. B) Effect of doxorubicin on cell number of MCF7 cells transfected with the p17-InN-LOV- $\Delta 6$ InC-p12 plasmid incubated in the dark or under blue light. C) Effect of doxorubicin on the ratio of living cells versus total particles in MCF7 cells transfected with p17-InN-LOV$\Delta 6$ InC-p12 plasmid, incubated in the dark or under blue light.

spliced extein (Supplementary Figure 7), further indicating that the high affinity of the Npu split-intein fragments overrides any conformational inhibition of splicing when LOV is in its dark state.

\section{Light-activated intein splicing in human cells.}

We next sought to assess the possibility of using the InN-LOV$\triangle 6 \mathrm{InC}$ for photo-activated splicing in human cells. MCF7 breast cancer cells are deficient in caspase 3 (due to a deletion mutation in exon 3 of its gene), ${ }^{24}$ and the absence of caspase 3 is required for the resistance of MCF7 cells to the chemotherapeutic agent Doxorubicin; the introduction of a plasmid encoding caspase 3 into MCF7 cells is sufficient to resensitize them to doxorubicin and trigger apoptosis. ${ }^{25}$ We sought to use this property to demonstrate photocontrolled unmasking of caspase 3 function with our $\ln N-L O V-\Delta 6 \ln C$ in MCF7 cells. Caspase 3 has been previously demonstrated to be functionally reconstitutable when split between its p17 and p12 domains (amino acids D175 and S176). ${ }^{26}$ We therefore generated a plasmid that encoded these two halves of caspase 3 as exteins that flank the sequence encoding the InN-LOV$\triangle 6 \mathrm{InC}$ protein. The encoded fusion protein would be expected to splice in the presence of blue light to reconstitute functional caspase 3 , causing a reduction in the viability of MCF7 cells in the presence of doxorubicin.

MCF7 cells were transfected with the plasmid encoding a p17InN-LOV- $\Delta 6 \operatorname{lnC}$-p12 fusion protein, and incubated in the dark

for 24 hours. These cells were then incubated either in the dark or under blue light for 3 hours, in the presence or absence of $10 \mu \mathrm{M}$ doxorubicin. Significant loss of cell viability was observed in the micrographs of cells incubated in the presence of blue light and doxorubicin compared to those incubated in the dark; there was no difference between samples incubated with blue light or in the dark in the absence of doxorubicin (Figure 3A). This observation was confirmed when the number of cells was quantified under each condition; $1.20 \times 10^{5} \pm 2.0 \times 10^{4}$ cells were present when transfected MCF7 cells were cultured in blue light, but in absence of doxorubicin, and $1.10 \times 10^{5} \pm 1.8 \times 10^{4}$ cells were present for equivalent samples incubated in the dark, showing no effect on cell viability from blue light alone. In the presence of $10 \mu \mathrm{M}$ doxorubicin however, a $35 \%$ reduction in cell number was observed in the presence of blue light; there were $1.18 \times$ $10^{5} \pm 1.6 \times 10^{4}$ cells present when transfected MCF7 cells were cultured in the dark, with $7.69 \times 10^{4} \pm 7.9 \times 10^{3}$ cells present in samples cultured under blue light (Figure $3 \mathrm{~B}$ ). The ratio of live cells versus total particles (arising from cell death and apoptosis) was quantified with a microfluic-based cell counter. In the absence of doxorubicin, no difference was observed in this ratio for cells incubated in the dark $(0.70 \pm 0.06)$ or under blue light $(0.75 \pm 0.04)$ indicating that blue light in combination with the $\mathrm{p} 17-\mathrm{InN}-\mathrm{LOV}-\Delta 6 \mathrm{InC}-\mathrm{p} 12$ protein was not sufficient to trigger cell death (Figure $3 \mathrm{C}$ ). In the presence of $10 \mu \mathrm{M}$ doxorubicin however, a $42 \%$ reduction in this ratio was observed for cells under blue light $(0.41 \pm 0.08)$ versus those incubated in the dark $(0.70 \pm 0.05)$. This data further indicates that blue light triggers splicing of the $\mathrm{p} 17-\mathrm{InN}$-LOV- $\Delta 6 \operatorname{lnC}-\mathrm{p} 12$ protein to give active caspase 3 , which sensitizes MCF7 cells to doxorubicin and results in cell death (Figure $3 \mathrm{C}$ ).

\section{Conclusions}

Taken together, the above data demonstrates that the $\ln N$ LOV- $\triangle 6 \operatorname{InC}$ protein combines the function of the light sensitive LOV2 domain with that of the Npu split-inteins, to enable allosteric control of protein splicing with blue light in $E$. coli and in human cells. It should be noted that although the magnitude of light-activation of splicing is relatively modest ( 2.5-fold), this is achieved using the light induced conformational change of the $\operatorname{lnN}$-LOV- $\Delta 6 \ln C$ fusion protein, which consists of only the 20 proteinogenic amino acids. Furthermore, the level of photocontrol observed here is in line with a previous report that used LOV2 to control the activity of dihydrofolate reductase with light, ${ }^{27}$ and a recent report that uses LOV-fused $\mathrm{Npu}$ inteins for photocontrol of trans splicing. ${ }^{20}$ This level of photocontrol by $\operatorname{lnN}-\mathrm{LOV}-\Delta 6 \ln C$ is therefore likely to be an inherent property of the LOV-intein fusion protein, rather than a result of the chosen extein. It should be noted that our data suggests this level of photoswitching is sufficient for the induction of cellular phenotypes with light. InN-LOV$\Delta 6 \mathrm{InC}$ may therefore be utilized for a variety of biological studies, especially given the relative ease with it can be deployed in a variety of systems. 


\section{Materials and Methods}

All reagents were purchased from ThermoFisher unless otherwise stated. UV-Vis spectra were recorded on a Vairan Cary 100. Cell culture reagents were purchased from Life Technologies unless otherwise stated. MCF7 cells were sourced from the American Type Culture Collection and not grown continually for more than 3 months. Cells were cultured at $37 \mathrm{C}$ in a humidified $5 \% \mathrm{CO} 2$ atmosphere in DMEM containing $10 \%$ fetal bovine serum (FBS) and $1 \%$ penicillin/streptomycin.

\section{Plasmid construction}

All genes were synthesized de novo by Integrated DNA Technologies. The amino acid sequence of the light switchable InN-LOV- $\triangle 6$ InC protein is given in supplementary information. The KanR protein was fragmented in two between F188 and S189, and Caspase 3 was split between D175 and S176. The genes used for $E$. coli expression were inserted into $\mathrm{PRSET}$, the T7 promoter of this plasmid was replaced with a constitutive promoter. The genes used in human cell studies were cloned into the backbone of pEGPF-N1 (the eGFP gene was removed).

\section{Light/dark growth of samples}

Plasmids were transformed in to $\mathrm{E}$. coli, and after recovery, incubated overnight at $37^{\circ} \mathrm{C}$ in darkness with shaking, in media containing $100 \mu \mathrm{g} / \mathrm{mL}$ of carbenecillin. 1\% of the overnight culture was plated onto LB agar plates containing $25 \mu \mathrm{g} / \mathrm{mL}$ of Kanamycin and $100 \mu \mathrm{g} / \mathrm{mL}$ of carbenecillin. These plates were divided into two sets and incubated at $37^{\circ} \mathrm{C}$ for 16 hours, either in the dark, or under blue light. Plates grown under light were illuminated with an LED array composed of high-emission low power InGaN bulbs (Supplementary Figure 1C). The light intensity was $\sim 5 \mathrm{~mW} / \mathrm{cm}^{2}$.

\section{Measuring intein splicing by western blot.}

An overnight culture of $\mathrm{E}$. coli containing the appropriate plasmid was used to inoculate $2 \times 500 \mathrm{~mL}$ of LB (1:200 dilution). Once the OD600 of the cultures had reached 0.6 they were separated in two. The first flask was incubated with shaking at $18^{\circ} \mathrm{C}$ overnight in a darkroom (to exclude light). The second was incubated with shaking at $18^{\circ} \mathrm{C}$ overnight, under blue light (Supplementary Figure 1D). Each culture was harvested by centrifugation at 4000rpm and the pellets were frozen at $80^{\circ} \mathrm{C}$. Pellets were lysed using lysis buffer (Imidazole $400 \mathrm{mM}$, $0.5 \mathrm{M} \mathrm{NaCl}, 50 \mathrm{mM}$ Tris- $\mathrm{HCl}, \mathrm{pH} 8.0$ ) in the dark. The resulting lysate was separated from cell debris by centrifugation and filtered using a sterile syringe filter (Millipore UK). Proteins were analyzed by SDS-PAGE and western blot as detailed below.

\section{Protein Immunoblotting}

Cell lysates were prepared as above, with the protein content of each sample quantified using the Bradford assay. Proteins were separated on $12 \%$ SDS-polyacrylamide Bis-Tris gels under denaturing conditions, transferred to unsupported pure nitrocellulose membrane (Amersham) and subjected to immunoblot analysis. Mouse monoclonal antibody raised against the 6-histidine epitope tag present on the $\mathrm{N}$-terminus of the extein (Novus, 1:2,500) were used for blotting. A mouse antibody raised against $\beta$-lactamase (Novus, 1:1,000), which is expressed from the same plasmid as the light-activated intein was used as a loading control. Antibodies were incubated with the membrane overnight at $4{ }^{\circ} \mathrm{C}$. Horseradish peroxidaseconjugated anti-mouse immunoglobulin $\mathrm{G}$ antiobody (Novus, $1: 10,000)$ was used as the secondary antibody. Bound immunocomplexes were detected using ECL prime western blot detection reagent (GE Healthcare) and analysed using Image Lab 4.0 (Bio-Rad). Molecular mass of visualized proteins was confirmed using molecular markers (for example image see Supplementary Figure 8).

\section{Kinetics of photo-adduct decay}

Recombinant LOV-intein proteins were expressed as above, and purified in a darkroom using FPLC and a Nickel affinity column (GE). Proteins were removed from the column with elution buffer ( $1 \mathrm{M} \mathrm{NaCl}, 400 \mathrm{mM}$ imidazole, $100 \mathrm{mM}$ Tris- $\mathrm{HCl}$, $\mathrm{pH}$ 8.0). the purified proteins were dialyzed into analysis buffer (Sodium Phosphate $10 \mathrm{mM}, \mathrm{NaCl} 10 \mathrm{mM}, \mathrm{pH}$ 8.0), followed by filtration (Millipore UK). Samples were kept in darkness at all times. Photo-adduct recovery was measured by UV-Vis spectroscopy at $25^{\circ} \mathrm{C}$. For a dark state spectrum, the sample was left in the UV-Vis spectrometer in total darkness for 10 minutes to ensure depletion of any photo-activated adduct. The absorption spectrum $(360-510 \mathrm{~nm})$ of the proteins was then measured. For light state spectra, samples were exposed to the LED array for 5 minutes and scanning UV-Vis absorption spectra (360-510nm) were continuously recorded for 600 seconds immediately afterwards. Photo-adduct levels were calculated as $1-(A t-A 0) /(A \infty-A 0)$, where $A t, A \infty$, and $A 0$ are absorptions at $450 \mathrm{~nm}$ at time $t$ in seconds, in darkness, and under blue light, respectively. The logarithm of the remaining photo-adduct level was plotted against to indicate the fast and slow components of reversion kinetics. The the decay rate of the $\mathrm{C}(4 \mathrm{a})$-cysteinyl adduct was determined using the absorption spectrum of the samples after exposure to the LED array. The absorption at $447 \mathrm{~nm}$ was used to determine the half-life of the adduct using $t 1 / 2=t \times \ln (2) / \ln (A t / A 0)$, where $t$, $A$ and $\mathrm{A} O$ are time, absorption at time $t$ in seconds and at time 0 respectively. The rate of photo-adduct decay was determined to be first order or pseudo first order for all samples half lives were quantified from the photo-adduct decay plots using Prism 6 (Graphpad).

\section{Transfection, cell treatments and cell counting}

Cells were transiently transfected with the p17-LOV- $\Delta 6$ inteinp12 plasmids using FuGENE HD (Promega) according to the manufacturers' instructions. Transfected cells were incubated in the dark for $24 \mathrm{~h}$, then treated with $10 \mu \mathrm{M}$ doxorubicin then either kept in the dark or exposed to blue light for $3 \mathrm{~h}$. Visualization of treated cells under phase contrast was carried out with a Zeiss Axio Vert.A1 microscope at $20 \mathrm{X}$ and $40 \mathrm{X}$ magnification. Cell counts and live/dead cell ratios were obtained using a Moxi Z Mini automated cell counter (Orflo). 


\section{Acknowledgements}

This work was funded by the Engineering and Physical Sciences Research Council (EP/H04986X/1 to AT) and the University of Southampton (Ph.D. studentship for DCJ and INM).

\section{References}

(1) Buskirk, A. R.; Ong, Y. C.; Gartner, Z. J.; Liu, D. R. Proceedings of the National Academy of Sciences of the United States of America 2004, 101, 10505.

(2) Mootz, H. D.; Blum, E. S.; Tyszkiewicz, A. B.; Muir, T. W. Journal of the American Chemical Society 2003, 125, 10561.

(3) Mootz, H. D.; Muir, T. W. Journal of the American Chemical Society 2002, 124, 9044.

(4) Skretas, G.; Wood, D. W. Protein Sci 2005, 14, 523.

(5) Wood, D. W.; Wu, W.; Belfort, G.; Derbyshire, V.; Belfort, M. Nat Biotechnol 1999, 17, 889.

(6) Zeidler, M. P.; Tan, C.; Bellaiche, Y.; Cherry, S.; Hader, S.; Gayko, U.; Perrimon, N. Nat Biotechnol 2004, 22, 871.

(7) Adam, E.; Perler, F. B. J Mol Microb Biotech 2002, 4, 479.

(8) Berrade, L.; Kwon, Y.; Camarero, J. A. Chembiochem : a European journal of chemical biology 2010, 11, 1368.

(9) Bocker, J. K.; Friedel, K.; Matern, J. C.; Bachmann, A. L.; Mootz, H. D. Angewandte Chemie 2015, 54, 2116.

(10) Cook, S. N.; Jack, W. E.; Xiong, X. F.; Danley, L. E.; Ellman, J. A.; Schultz, P. G.; Noren, C. J. Angew Chem Int Edit 1995, 34, 1629.

(11) Ren, W.; Ji, A.; Ai, H. W. Journal of the American Chemical Society 2015, 137, 2155.

(12) Vila-Perello, M.; Hori, Y.; Ribo, M.; Muir, T. W. Angewandte Chemie 2008, 47, 7764.

(13) Gautier, A.; Gauron, C.; Volovitch, M.; Bensimon, D.; Jullien, L.; Vriz, S. Nature chemical biology 2014, 10, 533.

(14) Halavaty, A. S.; Moffat, K. Biochemistry 2007, 46, 14001.

(15) Lockless, S. W.; Muir, T. W. Proceedings of the National Academy of Sciences of the United States of America 2009, 106, 10999.

(16) Iwai, H.; Zuger, S.; Jin, J.; Tam, P. H. FEBS letters 2006, 580, 1853.

(17) Zettler, J.; Schutz, V.; Mootz, H. D. FEBS letters 2009, $583,909$.

(18) Cheriyan, M.; Pedamallu, C. S.; Tori, K.; Perler, F. J Biol Chem 2013, 288, 6202.

(19) Schwartz, E. C.; Saez, L.; Young, M. W.; Muir, T. W. Nature chemical biology 2007, 3, 50.

(20) Wong, S.; Mosabbir, A. A.; Truong, K. Plos One 2015, 10, e0135965.

(21) Swartz, T. E.; Corchnoy, S. B.; Christie, J. M.; Lewis, J. W.; Szundi, I.; Briggs, W. R.; Bogomolni, R. A. J Biol Chem 2001, 276, 36493.

(22) Ghosh, I.; Sun, L.; Xu, M. Q. J Biol Chem 2001, 276,
(23) Alexandre, M. T.; van Grondelle, R.; Hellingwerf, $K$. J.; Robert, B.; Kennis, J. T. Physical chemistry chemical physics : PCCP 2008, 10, 6693.

(24) Janicke, R. U.; Ng, P.; Sprengart, M. L.; Porter, A. G. J Biol Chem 1998, 273, 15540.

(25) Yang, X. H.; Sladek, T. L.; Liu, X.; Butler, B. R.; Froelich, C. J.; Thor, A. D. Cancer research 2001, 61, 348.

(26) Chelur, D. S.; Chalfie, M. Proceedings of the National Academy of Sciences of the United States of America 2007, 104, 2283.

(27) Lee, J.; Natarajan, M.; Nashine, V. C.; Socolich, M.; Vo, T.; Russ, W. P.; Benkovic, S. J.; Ranganathan, R. Science 2008, 322, 438. 24051. 